\title{
THE MECHANICS OF PARAFFIN SECTIONING BY THE MICROTOME
}

\author{
WIIFRID TAYLOR DEMPSTER \\ Hepartment of Anatomy, University of Michigan, Ann Arbor \\ SEYENTEFN FIGURES
}

Microtome sectioning involves a type of cutting action akin to that produced by a hand plane, a lathe, or a knife in whittling. Forces are transmitted by the anterior beveled surface of the blade near its edge, and these forces dislodge a superficial layer of the material subjected to the cutting action. This type of cutting may be contrasted with cutting involving more than one surface of the tool - the chopping and splitting by an ax or the slicing of bread.

An engineering literature (Coker and Chakko, '22; Coker and Filon, '31; Boston, '33; Okoshi and Fukui, '33; and Ernst, '38) has dealt with factors in superficial cutting, but conditions have been so different from those in microtome sectioning that the information may be transferred to only a limited extent. Then too, the primary concern in metal cutting has been directed to surface finish, machinability and the efficient use of power rather than to the mode of chip formation. In microtome sectioning, the chip or section is of major interest.

The primary problem to be considered here is a qualitative analysis of what happens when a microtome knife removes a section of paraffin. Before this may be attacked, however, prior attention must be directed to (1) certain commonly ignored characteristies of the knife edge, and (2) some pertinent properties of the material to be sectioned. Paraffin as the most common embedding matrix will receive primary attention. Though homogeneous masses of paraffin are empha 
sized, the basic conclusions relate also to practical sectioning of tissues embedded in paraffin and to the sectioning of other matrices as well.

\section{THE KNIFE EDGE}

Ideal sharpness in a knife may be visualized as the convergence of the beveled facets to a mathematically exact bevel angle. Actually, however, due to the failure of the metal crystals at a knife edge, the bevels do not converge to an exact acute angle. This failure, following Kisser ('27) and von Ardenne ('39), may be defined in terms of the average radius of edge curvature of the actual edge. A small average radius of edge curvature implies relative sharpness or closeness to a mathematically exact bevel. These authors, respectively, have given figures of 0.3 and $0.1 \mu$ as the radius of curvature of a maximally sharp microtome knife. Such measurements are based on edge reflections or on sections through wax or metal impressions of an edge. Since the figures, however, represent measurements at or beyond the limit of resolution of the microscope using visible white light, they lack value as measurements but suggest instead that a convenient standard for edge sharpness is provided by the maximum resolution of the microscope to visible light. Thus, if the edge is examined edge on, it approaches a standard sharpness as edge reflections from a small source of light are reduced to a barely perceptible and even line.

Facet bevels as obtained commercially are arbitrarily standardized and there are apparently no data available as to the best angle for the various types of precision or routine sectioning. A group of knives at this laboratory varied in bevel angle from $19^{\circ}$ to $35^{\circ}$ with angles near $28^{\circ}$ being most common.

Three angles (fig. 1 A) are of significance with the rotary microtome: 1, the bevel angle; 2 , the clearance angle, that between the inner knife facet and the plane of the block face; and 3 , the rake angle, the angle between a plane perpendicular to the block face and that of the outer honed facet. For a given 
knife bevel, the rake and clearance angles are reciprocally related; the sum of the rake angle, the bevel angle and the clearance angle amounts to $90^{\circ}$.

It was shown separately by comparative measurements (Dempster, in press) that sections of homogeneous paraffin without included tissue were less compressed if sectioned with a wide rake angle. As the rake was increased to $72^{\circ}$, the maximum used, distortion became significantly less and this diminished compression was particularly marked for thin sections. Obviously, large rake angles are possible only with thinly beveled knives and with small clearance angles. In the study mentioned, clearance angles as low as $1^{\circ}$ were effective if the inner facet was kept clear of gummy accumulations of paraffin. Richards ('42), however, gives evidence that a clearance angle of $4^{\circ}$ or more may be of advantage in certain types of actual tissue sectioning.

There is doubtless a limit to the fineness of bevel that may be useful. The average radius of edge curvature is presumably dependent on both the "quality" of steel in a knife and the narrowness of bevel to which a knife is honed. A knife edge was ground and honed from a strip of poor quality steel (band iron) and various bevels, $7^{\circ}$ and larger, were prepared. The radius of edge curvature, which was quite large for this material, was greater for narrow than for wide bevels. If edge failure and bevel are similarly related in high quality tool steel, information on the narrowest bevel compatible with specific average radii of curvature would be desirable. Bevels of $16^{\circ}$ or $17^{\circ}$ to $20^{\circ}$ are common in straight razors, razor blades and veneer cutting knives, so it may be presumed that effective edges are possible at bevel angles much below those common in microtomy.

In figure $1, \mathrm{~B}$, a knife edge is shown removing a section; the total forces exerted by the knife in cutting are diagrammed as a series of forces (arrows) normal to the surface of contact between the knife bevel and the paraffin. Opposing forces are also shown. If a knife had an ideal bevel, the micro-forces would have the identical direction along the whole line of 
paraffin contact to the very edge. In the actual knife, however, the edge is partly blunted as indicated by its average radius of curvature. Forces here would be directed in a different manner, that is, at a much reduced rake angle, from those characteristic for the beveled facet proper.

If a widely and a narrowly beveled knife of the same average radius of curvature are compared (fig. $1, \mathrm{C}$ ), it will be seen that the nominal rake angle is actually interrupted less in the case of the small rake $\left(\mathrm{X}^{\prime}\right)$ than where the rake is large $\left(\mathrm{Y}^{\prime}\right)$.

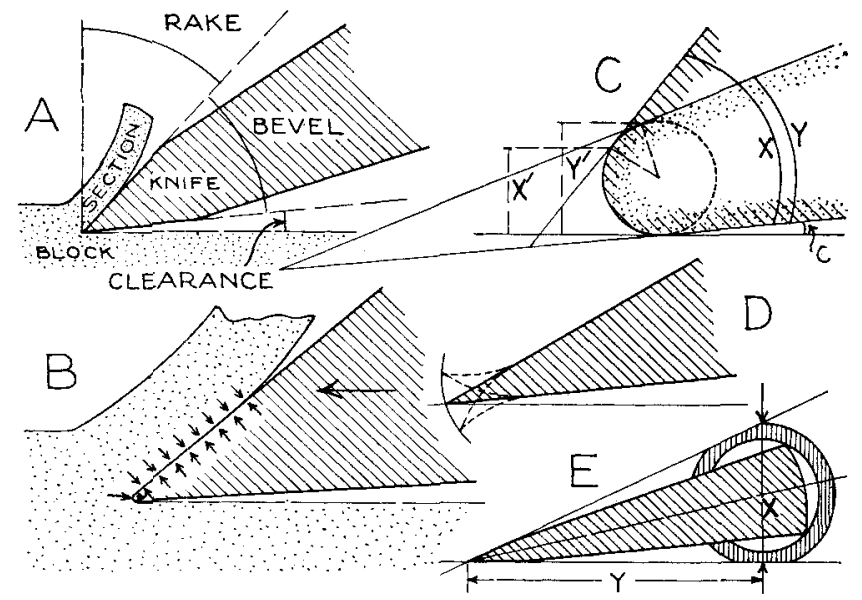

Fig. 1 Aspects of the knife edge. A. Definition of angles associated with knife settings. B. Region of transmission of eutting forces from knife to block and section. Forces, both eutting and resisting forces, are represented as arrows normal to the contact line. $C$. If $X$ and $Y$, respectively, indicate a wide and a narrow knife bevel with the same average radius of edge curvature, the interruption of characteristic rake $\left(\mathrm{X}^{\prime}\right)$ is less for the widely beveled knife than ( $\mathrm{Y}^{\prime}$ ) for the narrow bevel. D. Temporary displacements of an edge due to imposed forces. E. When a knife and sharpening back are laid on a flat support, the tangent of the bevel angle is the ratio: Measurement $X$

A further aspect of the knife edge that is augmented by thinness of bevel is edge displacement. For a given knife steel, the amplitude of edge movement due to elastic distortions of the knife edge by imposed forces (fig. 1, D), will be greater for narrowly beveled knives than for stouter types. 
Thus, opposed to the demonstrated superiority of narrow bevels in causing less section compression (Dempster, in press) and the theoretical justification of the narrow bevel (von Ardenne, '39), there are limiting factors dependent on edge elasticity and the radius of curvature of the edge (i.e., on the rake differential at the edge and along the outer facet). The problem of possible improvement of these limiting factors is one for the metallurgist.

For most effective sectioning, frictional resistance between a knife bevel and the section being cut should be low. Friction, like a low rake angle, increases compressive strains in the material ahead of a knife bevel. Efficiency implies a low paraffin to steel coefficient of friction and the highest possible facet smoothness.

For each type of sectioning, different types of resistance are met by the knife edge; for precision sectioning, several knives sharpened to different specific bevel angles should be available and should be appropriately selected for specific types of work. Embryonic tissue and other unresistant material, for instance, should be most effectively sectioned with small bevels (i.e., wide rake).

Figure 1, $\mathrm{E}$ shows a simple method of determining bevel angle; the ratio of measurements " $X$ " to " $Y$ " represents the tangent of the bevel angle and the angle may be determined and recorded on consulting trigonometric tables. If the edge to back width of a knife is known, the graph of figure 2 will allow the setting of a microtome to a desired clearance angle (cf. sketch and legend of fig. 2) on the basis of one simple measurement. The sum of the clearance and bevel angles if substracted from $90^{\circ}$ gives the rake. Through the aid of the graph, a tabulation of various nominal rake and clearance angles may be made in terms of the distance, perpendicular to the block face, between the block face and the mid-point of the heel of the knife.

For intelligent use of the microtome knife, five or possibly six factors should receive attention. These are: bevel angle, sharpness, facet polish, clearance angle, rake angle, and in 
the use of the sliding microtome, knife obliquity. The first three factors are determined during honing; the other factors relate to fixing the knife in the microtome.

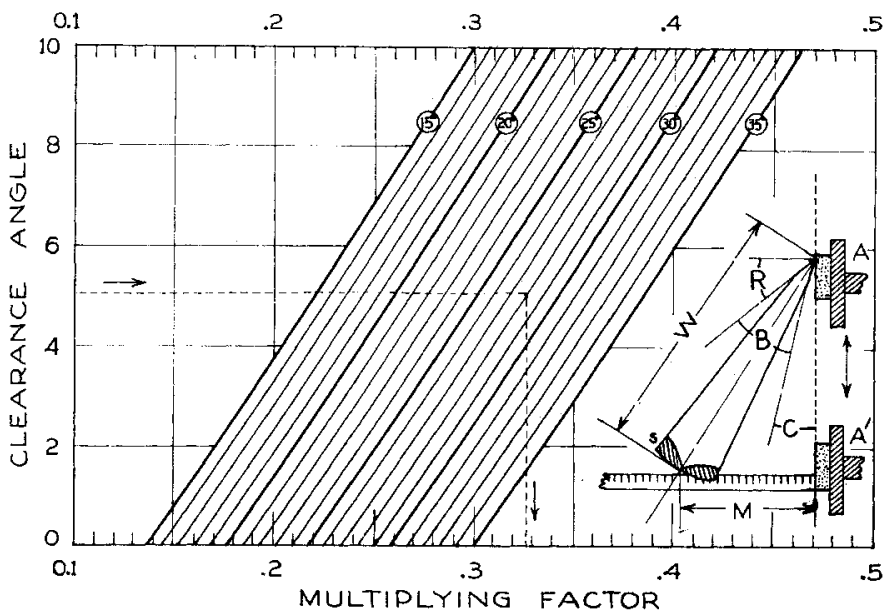

Fig. 2 Chart for determining clearance angle. For a desired elearance angle, e.g., $5^{\circ}$, follow horizontal line to right to intersection with oblique line representing bevel angle of knife at hand, viz., $28^{\circ}$; then follow vertical line to edge of chart, i.e., 0.327. This number multiplied by length $W$ (insert diagram) in millimeters gives the distance $\mathbf{M}$, in millimeters, between the block face and the midpoint of the heel of the knife. Notches in the heel of the knife (s) are helpful. While setting a knife, alternate the position of the block between $A$ and $A^{\prime}$.

\section{PERTINENT CHARACTERISTICS OF PARAFFIN}

Ordinary paraffin containing no adulterants, if allowed to solidify en masse as in routine embedding procedures, consists of closely packed rod-like crystalline units. Each crystal of the mass has an axial core surrounded by many alternate concentric lamellae of the harder and softer constituents of the paraffin mixture. The size of typical crystals is such $\pm 4 \mathrm{~mm} . \times \pm 0.1 \mathrm{~mm}$. diam. - that microtome sectioning divides the crystals into a number of slices. Since the characteristic erystalline structure provides a recognizable pattern, an analysis of the distortion and movements that occur in sectioning is possible. This is not as readily accomplished with more homogeneous materials such as celloidin or with other waxy materials. 
A microtome section shows a mosaic of crystal slices cut in all planes as would be expected for indifferently oriented crystals. The laminated crystal structure (fig. 3) is clearly shown if a section is momentarily flooded with amyl acetate; this dissolves away the softer paraffin and leaves a skeleton of

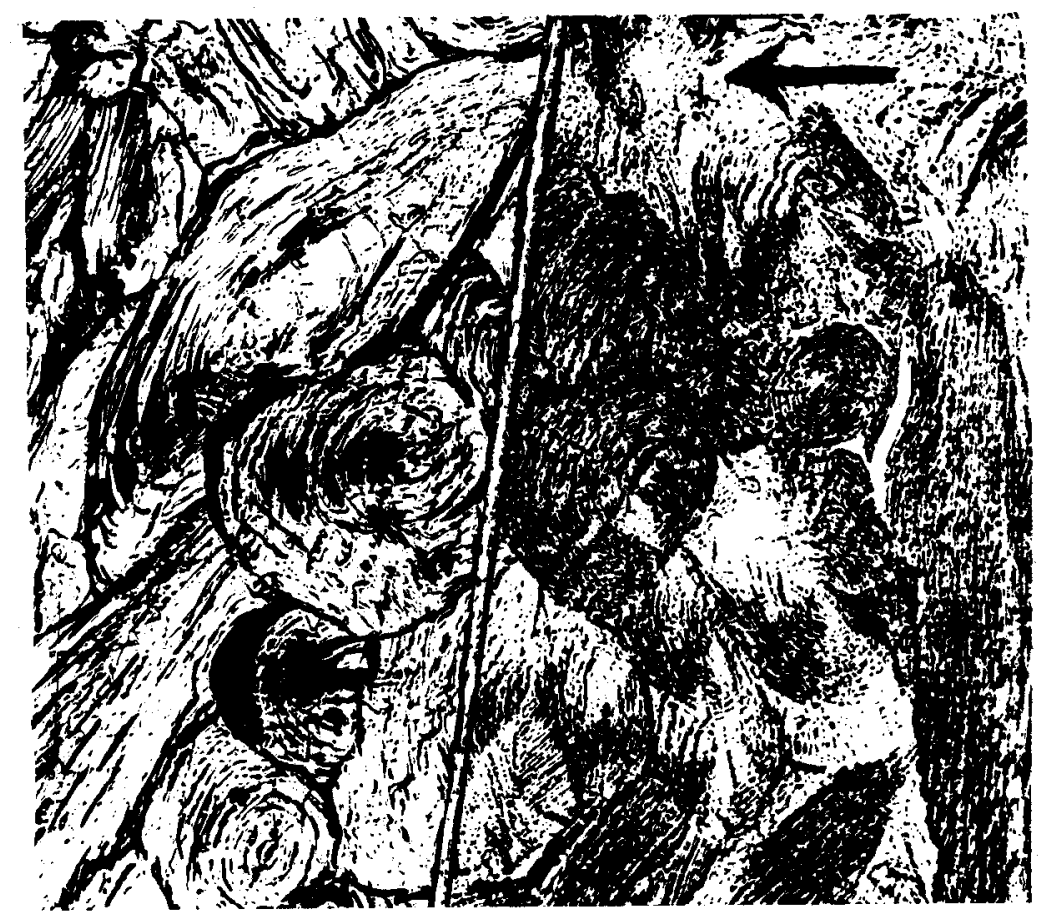

Fig. 3 Mosaic of paraffin crystal slices as seen in a $20 \mu$ section of $53-5^{\circ} \mathrm{C}$., m.p. paraffin. $\times 150$. Oblique, longitudinal and cross sections show suggestions of lamellar pattern. Black splotches and heavy lines indicate opacity deformation. At the right, flooding of the section with amyl acetate brings out the lamellar structure. Check lines, mostly transverse to direction of cutting (arrow), and stippling suggest disintegrative action of the knife on the lamellar pattern.

harder material. Detailed consideration of the structure and general properties of paraffin is given elsewhere (Dempster, in prep.), and specific attention needs to be directed only to the plastic behavior of paraffin and the mode of reaction to imposed force. . 
The plastic properties of solid paraffin, which peculiarly characterize the material, change throughout a thermal range. When paraffin is subjected to some specific compressive, tensile, or shearing force at different temperatures, a different type of response occurs above or below some critical temperature that will be called the plastic point. A compression test, adapted from a method of testing dental waxes (Am. Dental Ass'n specification no. 4; Skinner, '40) shows this.

Standard cylinders of paraffin $(6 \mathrm{~mm} . \times 10 \mathrm{~mm}$. diam.), cast in a split mould, are compressed over a period of 15 minutes by a standard $(2 \mathrm{~kg}$.) weight and the amount of compression of the cylinder is measured at intervals by a dial gauge. Below a critical temperature, compression is slight (fig. 4); above, it is increasingly marked. The specific plastic point and the values of the curve are duplicated only under specified conditions of testing. Shorter or longer application of the standard load gives a different curve; smaller or larger loads also produce different curves, each characterized, however, by a critical transition in paraffin response.

When paraffins of different melting point (m.p.) are tested at one constant temperature, a characteristic compression curve results for each (fig. 5). In general, compression is greater for low melting point paraffin than for paraffins of higher melting point but the two factors are not strictly correlated.

The amount of microtome section compression of different types of paraffin, determined by measurements of section length (Dempster, in press), follows, for equivalent section thicknesses, the order of plastic points. A higher melting point paraffin with a lower plastic point than another sample will compress more. Such behavior can account for the observation of Aumonier ('38) that a $58^{\circ} \mathrm{C}$., m.p. paraffin compressed more than a $52^{\circ} \mathrm{C}$., m.p. paraffin.

The plastic point, as a temperature above or below which paraffin shows a different mode of behavior to specific strains, becomes a measure of hardness or of relative resistance to 
imposed forces and is suggested as a practical measure, better than melting point, for correlating with sectioning behavior. If the type, magnitude and method of application of stress is properly standardized, plastic point should be helpful in distinguishing paraffins.

Compressed cylinders of paraffin are decreased in height and there is a compensatory increase in diameter. Such changes in shape are effected by slipping readjustments of
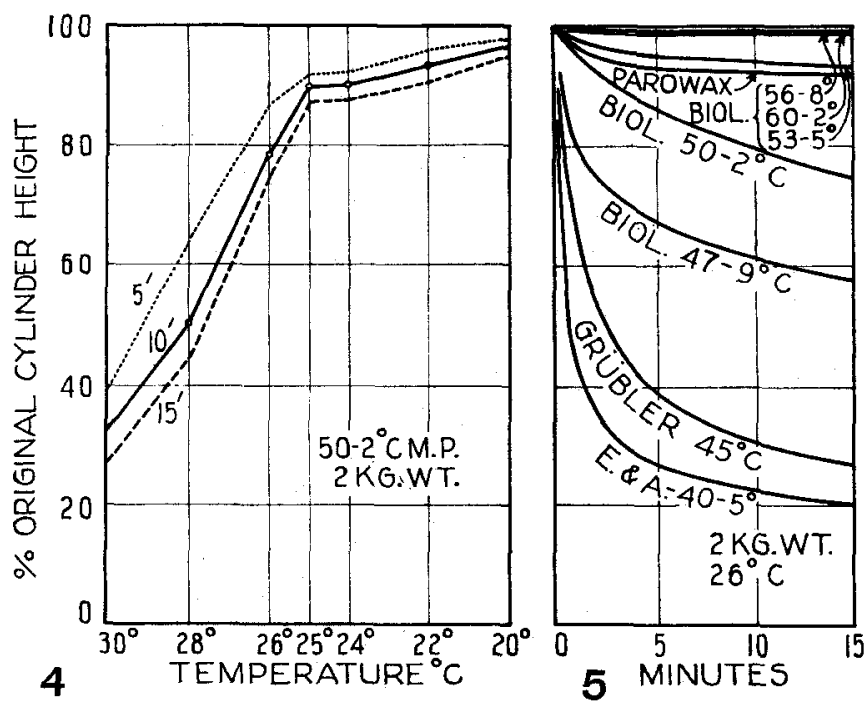

Fig. 4 Curves showing the degree of compression of standard cylinders of paraffin subjected to a continuous load at different temperatures. The amount of compression is shown after application of the weight for 5, 10 and 15 minutes.

Fig. 5 Compression curves representing the shortening of standard cylinders of various melting point paraffins under equivalent conditions. Biol. $=$ Will Corp. Bioloid paraffin; Parowax $=$ from Standard Oil Co.; E \& $\mathbf{A}=$ Eimer and Amend Co.; melting point ranges indicated by figures.

the relative position of the component crystals. If cylinder height is compressed $12 \%$ or more, erystal movements are accompanied by noticeable crystal distortion. With increasing degrees of compression to about $75 \%$, the lamellar pattern of crystals showed increasing disintegration (ef. fig. 3) ; the main body and particularly the axial region of crystals, however, maintained its essential integrity. With extreme cylinder flat- 
tening, all recognizable structure but the axial region of crystals was destroyed.

Since readjustments are effected by slipping movements of crystals in relation to one another and by varying degrees of intracrystalline distortion as well, one obviously must consider the resisting forces, that oppose deformation and prevent complete collapse of the material under stress, as operating both at crystal boundaries and within the substance of crystals. Thus, the resistance of cylinders to complete flattening under a compressing load is in reality the sum of the inter- and intra-crystalline resistances to shearing movements. Such resisting forces are cohesive in character and are relatively greater below a critical transition temperature than above.

The significant variables relating to paraffin plasticity, as indicated in figures 4 and 5, are: load, time of action of the stress, temperature, and resistance to distortion.

When paraffin is compressed suddenly by a large load - a hammer blow or compression between vice jaws - it becomes bruised and shows a whitish opacity unless the temperature is within about $20^{\circ}$ of the melting point. Opacity becomes marked at colder temperatures, and after cooling paraffin in ice water, it pulverizes or shows gross fractures. Opacity is due to minute cleavages and air spaces occurring both at intercrystalline junctions and at the peripheral (chiefly) lamellae of erystals.

Cleavages in stressed cold paraffin decrease the density of the paraffin materially. Volume measurements by water displacement (water containing the surface active agent terpitol), when made on $50-2^{\circ} \mathrm{C}$, m.p. paraffin rendered opaque at room temperature by a hammer blow, showed a $4 \%$ volume increment. Greater increments $(15-16 \%)$ were found when paraffin at room temperature or in ice water was shaved by a scalpel into fragments about $\frac{1}{2} \mathrm{~mm}$. thick. Opacity and decreased density did not appear or were negligible for similar shearing at a temperature of $38^{\circ} \mathrm{C}$. 
THE NATURE OF THE CUTTING REACTION

Photoelastic studies by Coker and Chakko ('22), Coker and Filon ('31) and Okoshi and Fukui ('33), though made to interpret aspects of metal cutting, provide some information on the nature and direction of forces active in all types of surface cutting. Stresses during cutting were computed and figured in stress diagrams like figure $6 \mathrm{~A}$ and $\mathrm{B}$.

The major forces exerted in cutting are differentially distributed through both the tool and the material being cut. As the radial distance from the line of tool-material contact,

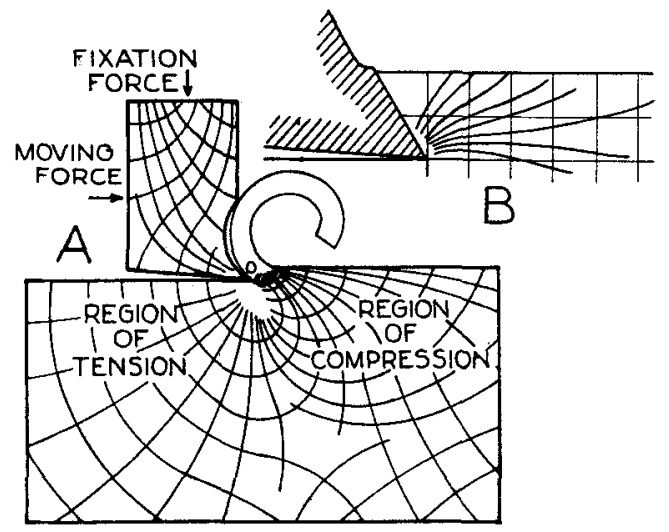

Fig. 6 A. Stress diagram of milling machine tool cutting a chip (modified from Coker and Filon). The shaded area near $O$ indicates the region of plastic deformation. $B$, Lines of principal shear in the region ahead of a knife edge (from Okoshi and Fukui).

"O," is increased, the stresses (force per unit area) are dispersed over a larger and larger area. Conversely, in the region near " $O$ " (shaded area), stresses acquire such magnitude that the elastic limit of the material being cut is exceeded. Permanent deformation or fracturing occurs here. It will be noted that the region of deformation is both below and above the level of the knife edge. Though the photoelastic method does not indicate the nature of the disturbance in a plastically deformed region, the stress pattern in neighboring regions is pertinent. Material ahead of the knife bevel is subjected 
to horizontal compressive stress. Behind the knife edge, in the region of the new surface, the material exhibits horizontal tensile stress. Material at and below the knife edge is lifted in a vertical direction by tensile forces. The resultant of forces ahead of the knife bevel may be shown as lines of principal shear as in figure 6, B. Movements of material due to sectioning may be expected to follow such shear lines.

Behavior in the plastically deformed region ahead of a knife bevel may be inferred from a study of rather thick $(2-3 \mathrm{~mm}$.) sections of paraffin. To produce such sections, a block of paraffin at some temperature $20^{\circ}$ or more below the melting point, is simply placed between vice jaws with 2 or $3 \mathrm{~mm}$. of the edge projecting above the jaws, and a knife or chisel edge, straddling the jaws of the vice, is shoved along at a constant velocity to detach a section.

As shown in figure 7 , sections acquire a segmental character as they form and curl at the knife edge. They consist of tranverse prisms of clear paraffin between which are thin regions (stipple and lines) of opaque paraffin. When sections are cut with a wide rake knife, the segments of clear paraffin extend through the whole thickness of sections. Their profile in the axis of knife movement (fig. $7 \mathrm{~A}$ and $\mathrm{B}$ ) is approximately rhomboidal. The laminae of opaque paraffin between the prisms are thin and even, except at their lower extremities where they become wider. Each prism slightly overrides the next in sequence so that a perceptible serration is evident on the free surface. Prisms, thus, shear and slip along lines of opaque paraffin. As the knife tilt is increased (fig. $7 \mathrm{C}$ and D), the opaque paraffin increases and slip planes appear to have encroached on the basal region of the clear prisms. These latter now have rounded basal regions and ordinarily do not extend through the whole thickness of the sections. As the knife rake is further decreased, the overriding of prisms along oblique $45^{\circ}$ planes results in more marked imbrication on the free surface. At a rake of $30^{\circ}$, as much of the corrugated outer surface is made of exposed slip plane as of the original paraffin surface. With a still further decrease in rake, the 
prisms of clear paraffin now have a roughly triangular cross section. As the knife rake is decreased to zero or beyond (fig. $7 \mathrm{~F}$ and $\mathrm{G}$ ), the opaque interprismatic paraffin is crushed and formed into a narrow strip which becomes moulded into the lower edge of each triangular prism.

Clear prisms, particularly those made with narrow rake knives are themselves deformed by cutting. When a section is flattened (fig. $7 \mathrm{~J}$ ), the segments separate partly and it becomes obvious that they could not be reassembled to form a
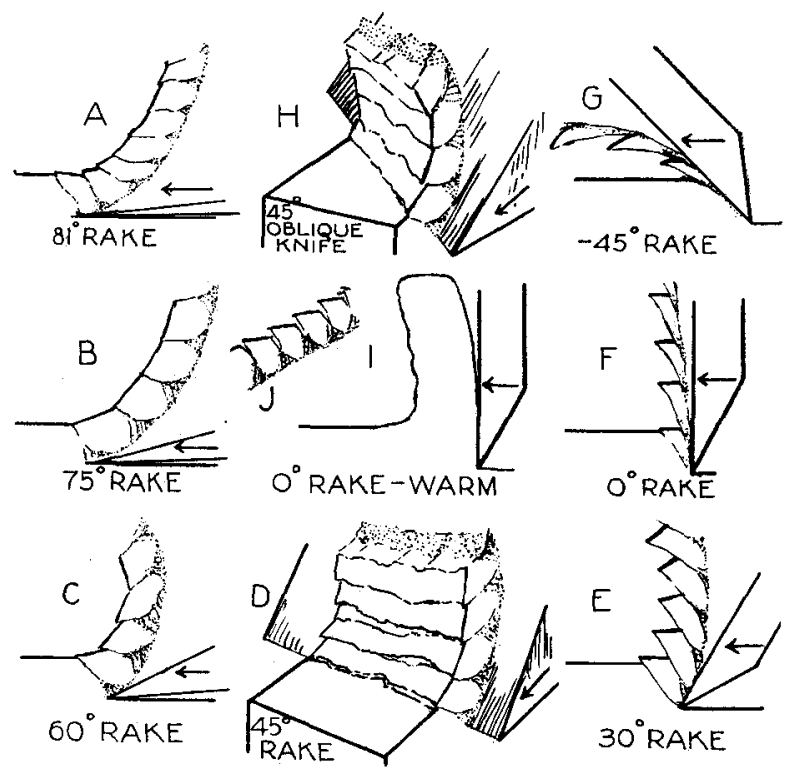

Fig. 7 Structure of thick paraffin sections for various knife rakes. Stipple and fine lines indicate regions of paraffin opacity. Arrows show direction of knife or chisel movement. At " $\mathrm{J}$ ', a section, $45^{\circ}$ rake angle, is shown uneurled and flattened.

continuous layer of paraffin without remoulding the shape of the prisms. Thus, sectioning involves, in addition to gross shearing movements over lines of opacity, minor shearing and moulding movements that do not involve opacity and ruptures. This moulding action increases as rake angles become narrower. 
As a segment of a section lifts upward to move across the face of a knife bevel, its direction is changed, and from a series of such segments a curled section forms. The inner side of the curl is compressed and the serrations at the surface are compensatory; the outer side is under tension. The forward movement of the knife and frictional forces as well, compact and crush, and for narrow rakes remould, this basal region of sections; in all cases, the basal surface of sections becomes burnished and shiny.

If the block from which sections have been removed is examined, one sees slight transverse grooves marring the surface. The more prominent are as far apart as the width, across the upper surface, of the clear prisms making up the section removed. Between these major grooves are four or five others which may be barely perceptible. Obviously, these markings are due to downward deflection of the knife edge during moments of slip plane formation. The major grooves are associated with the breaking off of clear prisms of paraffin and the minor with the secondary slip planes that appear in the basal regions of sections. When a knife edge is deflected downward by paraffin resistance, it acquires increasing amounts of energy which are suddenly released when the elastic limit of the overlying paraffin is exceeded. The springiness of the knife edge, in effect, pries up the paraffin and a slip plane is produced together with a shear movement of the newly formed prism of paraffin. Knife elasticity thus imparts an oscillatory rhythm to the forces active at a knife edge during cutting.

Ernst ('38) has illustrated exposures from a motion picture film of a narrow rake knife impinging on a block of paraffin in the first act of removing a section. At the point of impact as seen from the side, the paraffin is deformed and shows as a tiny opaque triangle extending above and below the knife edge with an apex directed forward in the axis of knife movement. The opaque triangle increases in size and the apex further invades the clear paraffin till finally a slip line or fracture, beginning at the apex of the triangular area, extends 
forward and upward to meet the surface of the paraffin being sectioned at an angle of about $45^{\circ}$. Thus, the first prism of paraffin is displaced, but the knife has scarcely entered the paraffin. Now, as shown in figure 7, the knife edge moves forward into the region from which the prism was broken. New slip planes of a minor type, often four to six of them in succession, form and course upward to meet the slanting surface of the first major slip plane, again at an angle of about $45^{\circ}$. By the time these reach a length of about half the section thickness, a long arching major slip line breaks through to the surface, and a second clear prism is removed. As the knife moves along, shearing several minor prisms and then a major one in alternation, forces are causing prism slippage, basal crushing, moulding, readjustments within prisms, and the burnishing of the basal surface of the section as indicated above.

Sections made above some critical temperature involve an entirely different type of cutting reaction. In warm sectioning, the sections are continuous, are relatively translucent and are shorter than equivalent sections made with colder paraffin (fig. 7 I). The type of cutting and the displacements of material by the knife edge are, in general, similar to those found in the continuous chip type of cutting of ductile metals (Ernst, '38). Built-up edges that may occur on the outer bevel of a tool in the cutting of ductile metals, however, do not occur with paraffin. The knife moves smoothly across the block and the paraffin responds by smooth shearing flow movements extending obliquely from the knife edge to some point on the surface a short distance ahead of the knife edge. This oblique plane of shearing, which limits the anterior end of a section as it forms, lies at about $45^{\circ}$ to the block surface and this seems to be true for all rakes. Along this plane, sliding and squeezing movements of crystals occur and the lamellar pattern of crystals is disturbed. Shear lines may traverse certain crystals. Transversely placed crystals ahead of a knife edge, as seen from the side, though not yet severed, are bowed and internally deformed. In thinner sections, ap- 
proaching a crystal diameter or less in thickness, crystal boundaries may become indistinct and the lamellar pattern becomes distorted. Distortion is effected by plastic flowing movements of the material of both crystals and intercrystalline junctions. When block temperature is lowered below the plastic point, opacity and discontinuous shear movements suddenly begin.

The energy involved in shear movements and the frictional forces between a knife and a section liberate heat. In a poor conductor such as paraffin a slight local increase in temperature could have only a localized effect in altering the plastic behavior of paraffin. In thin sections, even though the block and working temperature are relatively low, the thermal effect on plasticity, due to sectioning, is distributed over a larger proportion of the section thickness than for thick sections. Accordingly, the mode of sectioning follows the plastic flow (warm) type of eutting even at moderately low room temperatures. As sections are made thinner and thinner, the local warming effect increases materially. Crystal distortion becomes extreme and gross shortening of sections becomes marked. Some correction of this defect may be made by lowering block and particularly the knife temperature so that excess heat is absorbed. The local thermal effect is less also with paraffins of high plastic point.

In addition to warming effects that are particularly marked for thin sections, a local lowering of the temperature of transition may be expected due to the increased stress associated with thin sections. Bridgeman ('16) has shown that a solid subjected to any stress experiences a depression of the temperature of transition between two phases. If the stress differential is great enough, plastic flow is produced by actual local melting followed by regellation and the equalization of pressures in the component particles of the material subjected to strain.

A type of sectioning response that is most desirable in microtomy is a transition between warm and cold sectioning. It occurs only for rakes beyond about $50^{\circ}$ and for intermedi- 
ate thicknesses of sections (roughly 10 to 200 microns or more) when sections are made at temperatures just below the transition point. Narrower rakes and a marked decrease in temperature cause prismatic sections. Prism size is proportional to section thickness. The intermediate type of section has a velvety upper surface and a somewhat generalized opacity. Magnification shows this opacity and diffuse shearing effect to be located primarily at intercrystalline boundaries though minor opacities may appear within crystal outlines. The crystal slices are commonly tilted obliquely.

This type of sectioning, characteristic of wide rake angles and a suitable balance between paraffin plastic point and cutting temperature, produces less displacement of crystals, less deformation and less shortening of sections grossly than the typical warm or cold types of sectioning. Such sections, of course, adhere well to form ribbons with the rotary microtome. Shortening of sections amounts to $20 \%$ or less of block length. This diffuse intercrystalline type of shearing may be extended to the thinner range of sections somewhat by the reduction of local warming effects as indicated above.

\section{ASPECTS OF MICROTOME SECTIONING}

Various aspects of rontine sectioning may be illustrated by placing an elongate block of paraffin in the microtome, drawing a knife, set at a right angle to the axis of movement, almost across the length of the block and then withdrawing the knife. The block with the attached section is then removed and carefully laid on its side in an embedding box. A low melting point wax, having a distinctive crystal structure (diglycol stearate + soft paraffin ; 50:50) and preferably colored, is poured over the block and section. On cooling, microtome sections of about 25 microns thickness, are cut across the side of the block. Such sections of sections as illustrated in figures 8 to 12 represent sectioning at one room temperature.

Figure 8 shows the result of plastic flow in a 10-micron section. Slip lines, extending from the knife edge, proceed through the whole thickness of the section to meet the block 
surface at about $45^{\circ}$. Figure 9 shows a thicker section cut from the same block with evidence of intercrystalline slippage (at a) and plastic flow (at b). Such intercrystalline vacuities as that illustrated at "a," form the basis for opacity. In figure 10, the split below the crystal at the knife edge is further
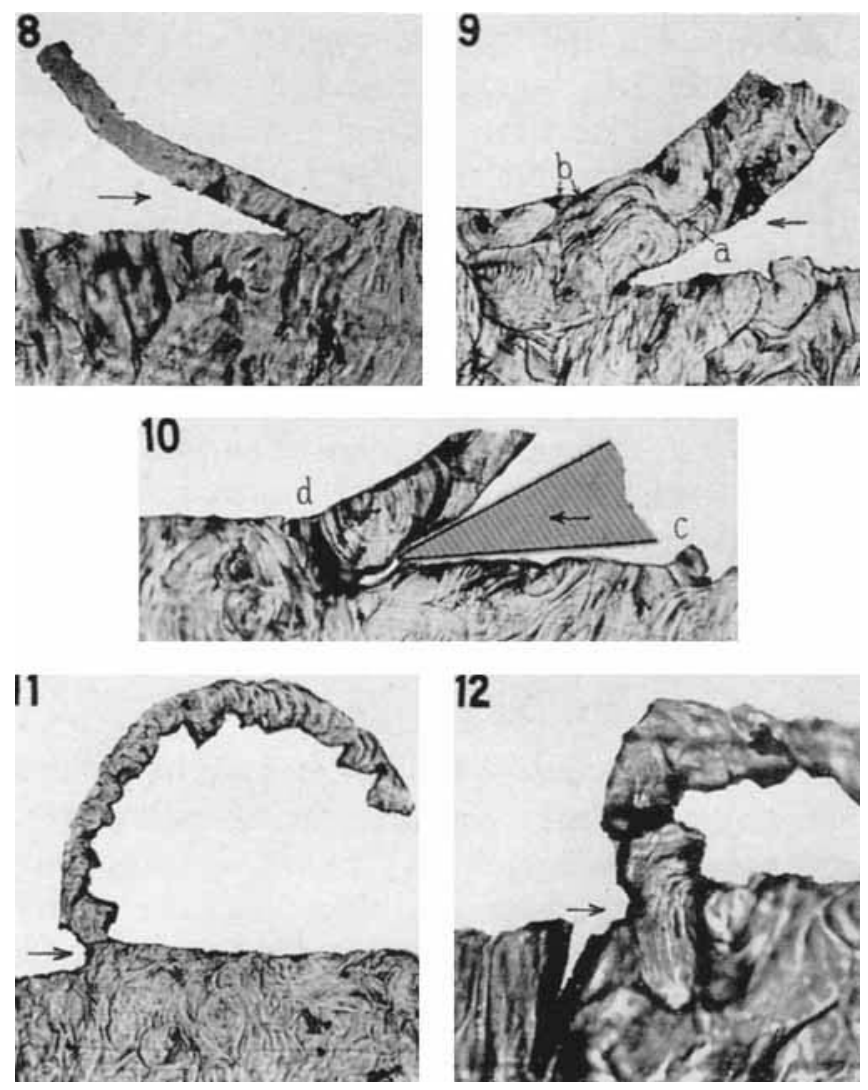

Fig. 8 Longitudinal section through a 10-micron paraffin section and block showing distortion due to sectioning. $\times 175$. This and the accompanying sections were made with a transverse knife at a rake of $60^{\circ} ; 56-8^{\circ} \mathrm{C}$. m.p. Bioloid paraffin; $27^{\circ} \mathrm{C}$. cutting temp.

Fig. 9 One hundred-mieron section seen in longitudinal section. $\times 100$. Distortions indicated by letters are discussed in text.

Fig. 10 Fifty-micron section. $\times 100$.

Fig. 11 Fifty-micron section made with a dull knife. $\times 50$.

Fig. 12 Thirty-micron section made with a dull knife. $\times 175$. 
evidence of intercrystalline movement - movement, however, in this case, associated with rupture at a crystal boundary. This is shown, likewise, by the crystal to the right at "c". Planes of plastic slip are evident at " $d$ ". The protruding ends of crystals left at the block surface suggest a breaking of crystals, one by one, by slip planes acting reasonably close to the plane of knife edge movement.

Figures 11 and 12 illustrate the effect of cutting with a very dull knife edge. Planes of slip similar to those shown above in figure 7 for thick sections cut with a knife rake of $0^{\circ}$ to $30^{\circ}$ are clearly evident even though the nominal knife rake was the same as that used for the other sections, and cutting was done in an identical room temperature. These figures indicate that a dull knife has the same effect as a strong reduction in rake of a sharp knife. Conversely, it may be assumed that the effect of a sharp knife in microtomy is to allow a constant rake to exert simple, unmodified shearing forces to the very edge of the knife.

Figure 12 is remarkable, in addition, for showing a knife edge impinging on a crystal in such a way as to suggest the mode of action of cutting forces (cf. photoelastic method, p. 251). The region ahead of the split appears to be horizontally compressed, that behind is tensed. There is an obvious lifting and prying effect (vertical tension) on the crystal ahead of the knife edge. Intracrystalline shear lines are suggested.

When sections showing various degrees of shortening are viewed normally, the amount of paraffin crystal distortion is seen to be proportional to the degree of compression in section length. Figures 13 to 16 show the change in crystal pattern for four different section thicknesses. In thicker sections, small interstitial crystals and crystals lying parallel to the knife edge are compressed most, while crystal cross sections maintain their shape and structure. With the greater distortion of thinner sections, crystal cross sections appear compressed and the peripheral regions break down. Meanwhile, longitudinal crystals are further distorted. In very thin sec- 
tions, all evidence of crystalline structure disappears except crystalline cores and a few adjacent lamellae (fig. 16). Crystal distortion in sections is thus very much like the distortion found with cylinders of paraffin subjected to compressing loads.

Intercrystalline junctions give way and crystal slices come to occupy oblique planes in the section. This is shown in the dark transverse crystals of figure 14, in which the loss of brightness is due to the refraction of light away from the lens of the microscope. Crystal edges last to pass over the knife
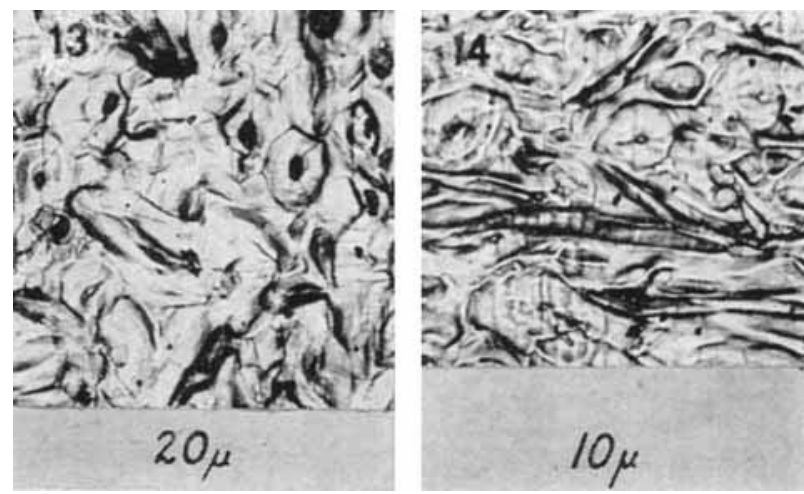

F'ig. 13 Structure of a slightly compressed paraffin section (to 83\%) showing crystal cross sections with prominent axial regions and hexagonal boundaries. The lower gray area indicates the amount of section shortening as compared to original block size. $50-2^{\circ} \mathrm{C}$. m.p. paraffin; $24^{\circ} \mathrm{C}$. cutting temp.; $\times 100$.

Fig. 14 A more compressed section (to $75 \%$ ).

edge are raised to produce a shingle-like surface. This imbrication becomes pronounced with small knife rakes or with moderately great compression.

Intracrystalline plastic readjustments which oceur within crystal slices are illustrated best in cold sectioning. One part of the crystal slides against another along slip planes. Usually groups of parallel slip planes (fig. 17) are found. Ordinarily, they form transversely to the axis of knife movement and are particularly prominent in crystals with long axes in the axis of knife movement. Slip planes also may follow the lamellae of the crystal pattern. The surface overlying groups of slip 
lines, as shown by oblique reflected illumination, is thrown into parallel ridges like the surface of a file. Such distortions may be accounted for by intracrystalline plastic shearing movements of a type extensively studied in relation to plastic flow in metals (Bingham, '22; Nádai, '31; Rosenhain and Haughton, '35; Houwink, '37; Crane, '39; and Andrade et al., '40).

With warm sectioning and with the cold sectioning of thin sections, such intracrystalline shear lines are not clearly evident. Instead, the pattern of crystal slices, and the intercrystalline junctions as well, is broken up by plastic or viscous flow movements of a submicroscopic character.
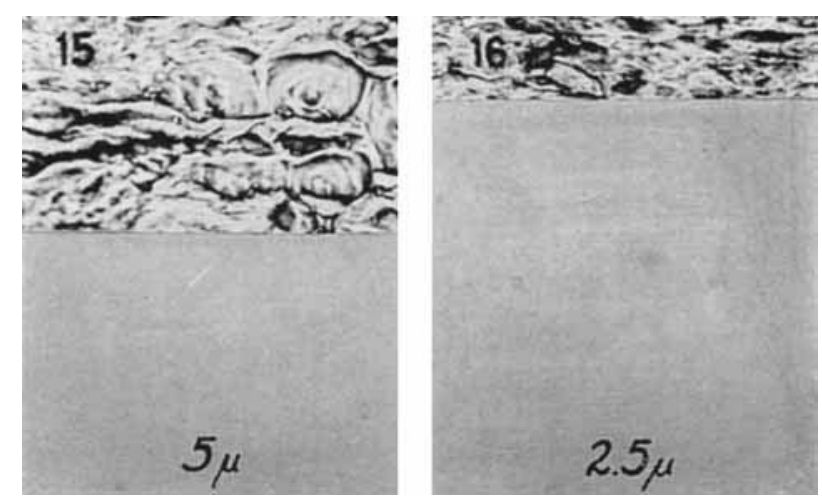

Fig. 15 A section compressed to $45 \%$ of block length. Crystal cross sections are still recognizable. Transversely, across the middle of the section is a junction between two sections in a ribbon. Distortion is more marked for the end of the first section (lower) than for the beginning of the second.

Fig. 16 An extremely compressed section, to $18 \%$, showing loss of all structure except for three or four crystal cores and adjacent lamellae.

Plastic shear lines and crystal imbrication give an uneven surface to sections and the surface appears velvety to the naked eye. Discontinuities, chiefly at intercrystalline boundaries, by their opacity contribute also to the velvety appearance; sections made at a sufficiently higher temperature are more translucent.

Both shear movements and the obliquity of crystal slices cause sections to be much thicker than the microtome setting. Decreased section length is in reality a compensation. 
Richards ('42) finds that section thickness is actually more than enough to compensate for section length if section volume is based on block area and microtome setting. This "excess thickness" is no doubt accounted for by opacity and the resulting decreased density.

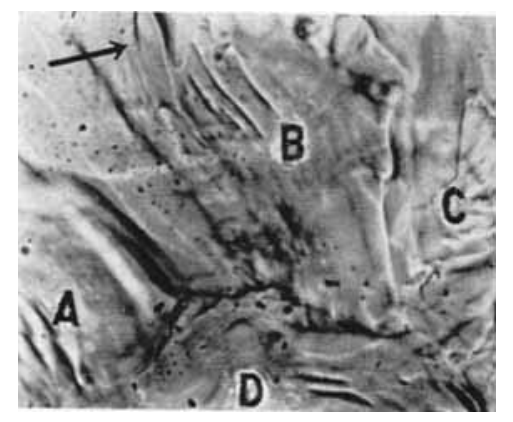

Fig. 17 Parts of four erystals of paraffin (A, B, C, D), each showing groups of intracrystalline slip lines. Arrow indicates direction of knife movement. $\times 450$.

\section{SECTIONING OF TISSUES}

Observations on a wide variety of animal tissues, infiltrated and embedded in paraffin, show that tissues participate in the cutting reaction in a manner quite the same as paraffin. In the cold cutting of intermediate and thick sections, the tissue is divided into segments; the shape of segments for specific rakes is like that for paraffin; the basal region of sections is similarly crushed. In warm sectioning, point by point shearing occurs. Like paraffin, thin sections of tissue show the effect of local warming by frictional heat and the distortions are more marked for the thinner sections. Under the special conditions for diffuse discontinuous shearing at temperatures near the plastic point there are some appearances that suggest similar action.

Differences between tissue and paraffin sectioning are largely differences in degree of response. Tissue embedded in paraffin provides a mesh, the constituent parts and interstices of which are permeated with paraffin. The material of 
the mesh is a gel and the pertinent properties of this gel -. renitency, hardness, brittleness - are dependent on the original nature of the tissue elements during life and the colloidal and chemical alterations due to fixation, dehydration, clearing and infiltration. Shrinkage and heat effects likewise may affect such properties. Thus, the physical characteristics of a tissue mesh are assuredly different from paraffin and one tissue (or fixation sequence) differs from another. The component resistances to cutting of a meshwork and its interstices may be expected to differ from the general matrix of paraffin.

In general, cleavages in the tissue meshwork do not occur as readily as in paraffin, unless the tissue is brittle, the rake angle small or the cutting temperature too far below the plastic point. Brittle tissue --yolk filled regions, colloid, etc. - may segment while the paraffin matrix adjusts by smooth plastic flow movements. Cartilage or a celloidin matrix infiltrated with paraffin, on the other hand, may show plastic flow movements while the matrix paraffin is sheared into segments. Masses of connective tissue may respond to cutting forces by fibrous tearing with a resultant opaque and disturbed block surface. The next section then is made through inadequately supported tissue. Due to the variable resistances of tissues, the amount of section shortening may be slight or extensive; tissue compression is rarely as extensive as the compression of sections of the embedding paraffin alone (Dempster, in press). Embryo tissue, however, offers so little resistance to sectioning that sections shorten about as much as for paraffin alone; corrugations in sections after floating, thus, are uncommon.

Obviously, effective sectioning calls for approximately the same elastic and plastic properties in both tissue and matrix. Avoidance of undue hardening by fixation and other procedures, the procedure of infiltrating in a low plastic point paraffin and embedding in a harder one and the appropriate adjustment of cutting temperature may be necessary prerequisites for suitable sections. Celloidin double embedding 
methods tend to induce, in otherwise brittle tissue, smooth plastic adjustments like those characteristic of celloidin alone.

The sectioning process characteristically imparts a curl to sections; the particles of both tissue and matrix are deformed in congruence with the curling distortion. If sections are thin or if sections are warmed or floated on water, they flatten, but the flattening process does not involve the same type of plastic change as that causing the curl, and transverse fractures may now occur. Thyroid colloid and intravascular clots, as seen in microscopical sections, often show this defect. It is illustrated also if hard wood shavings from a plane are uncurled and flattened.

Examination of microscopical sections with a view to recognizing and evaluating deformations due to sectioning is made easier if poor slices - brittle material, defective ribboning, scoring by a nicked knife - are selected. Minor deformations of sectioning, though present, are difficult to distinguish because superimposed on the sectioning defects are changes due to colloidal swelling adjustments occurring in flattening procedures and the staining sequence. These mask and in part compensate for the lesser sectioning defects (Dempster, in press).

\section{SUMMARY AND CONCLUSIONS}

The microtome knife is a surface acting cutting tool that removes a section by causing shearing movements in the material being cut. Two primary types of shearing response are characteristic in the sectioning of paraffin or of paraffin infiltrated tissues and the type of response depends on the working temperature. Cold sectioning, which is characterized by discontinuous shear movements of material, occurs below a particular critical temperature for each type of paraffin and warm sectioning, sectioning in which shear movements occur continuously in point to point sequence, appears above this temperature. With a relatively flat knife tilt and for intermediate thicknesses of sections, cold sectioning is effected by diffuse shear movements occurring primarily at the inter- 
crystalline boundaries of the paraffin matrix. For these special conditions, minimum total distortion is obtained. In the case of thinner sections, heat dissipation in the region of shearing elevates the temperature locally, and sectioning follows the warm type of reaction. Sections show considerable compression. Through the selection of suitably hard embedding matrices and by drawing off frictional heat (with a cold knife), it may be possible to reduce compression and transform the cutting response of thin sections from the warm to the intermediate diffuse shear type.

Paraffins of different hardness show varying degrees of resistance to shearing. Hardness may be determined through paraffin plastic points, that is, by the critical temperature above or below which paraffin responds in a different manner to some specified stress. Celloidin does not show a thermal response for thin sections like paraffin does; though the material is relatively resistant to distortion, it presumably sections by point to point plastic flow like warm paraffin.

Material embedded in paraffin may be considered as a gel in which the aqueous phase has been largely replaced by paraffin. It acts as a resilient web following the movements of the paraffin matrix but increasing the resistance to shearing flow. Section compression is less than for the matrix and this effect is more marked for dense tissues, such as cartilage or heart muscle, than for looser tissues, like embryonic material or lung. When tissue is rendered brittle by fixation and related procedures or contains inclusions that are not readily penetrated by paraffin, fracture lines and crumbling may result.

For a given material and matrix to be sectioned, the desirable aspects of a knife, as inferred from the foregoing, are:

1. As narrow a bevel as is consistent with a low average radius of edge curvature and a low amplitude of edge deflection under the resistances met in sectioning.

2. A low average radius of edge curvature. This is particularly important for thin sections. Knife acuity and a narrow bevel allow a wide rake angle to be effective over nearly the whole 
line of contact between the outer bevel and the material being eut.

3. A low resistance to the sliding of a section across the outer bevel. This implies bevel polish, freedom from scratches of appreeiable size and as low a coefficient of friction with the material being eut as is consistent with the other properties of the knife.

4. For thin sections, a cool enough knife edge to carry away frictional heat losses.

The first three characteristics have in common a reduction in the magnitude of an anteriorly directed compressive force on the material ahead of the knife bevel. If compressive forces are augmented by a blunt edge or a rough bevel surface, the effect is similar to a decrease in rake angle. A decrease in temperature, by altering paraffin resistance, has an indirect effect in increasing the magnitude of edge deflection. An increase in load, due to increased section thickness, has a similar effect. Temperature changes also alter the adhesiveness of paraffin to a knife bevel. The effectiveness of the water-on-theknife method of sectioning with the sliding microtome is probably as much due to the prevention of adhesion of sections to a knife as to surface tension effects.

\section{LITERATURE CITED}

ANDRADE, N. DAC. ET AL. 1940 Report of a conference on internal strains in solids held at the H. H. Wills Physical Laboratory, University of Bristol. I'roc. Physical Soc., vol. 52, pt. 1, pp. 1-178.

Von Ardenne, M. 1939 Die Keilschnittmethode, ein Weg zur Herstellung vom Mikrotomschnitten mit weniger als $10^{-3} \mathrm{~mm}$. Stärke für elektronen mikroskopische Zwecke. Zeit. f. wiss. Mikroskopie, Bd. 56, S. 8-23.

Auxonier, E. J. 1938 Notes on the distortion of paraffin sections. J. Roy. Micr. Soc., Ser. 3, vol. 58, pp. 253-257.

Brighan, E. C. 1922 Fluidity and plasticity, pp. 440, McGraw-Hill Book Co., N. $Y$.

Bridgeman, P. W. 1916 On the effect of general mechanical stress on the temperature of transition of two phases, with a discussion of plasticity. Phys. Rev. (Ser. 2), vol. 7, pp. 215-224.

Boston, O. W. 1933 Engineering and shop practice, vol. 1, pp. 539, John Wiley and Sons, N. Y.

Coker, E. G., AND K. C. Chakko 1922 An account of some experiments on the action of cutting tools. Proe. Inst. Mech. Engineers, vol. 1, pp. 567-621.

Coker, E. G., ANd L. N. G. Filon 1931 A textbook on photoelasticity, pp. 720, Cambridge University Press. 
Crane, E. V. 1939 Plastic working of metals and power press operations, pp. 450, John Wiley and Sons, N. Y.

Dempsren, W. T. Paraffin compression due to the rotary microtome, Stain Tech., vol. 18. (In press.)

(in prep.) Properties of paraffin relating to microtechnique.

Ernst, Hans 1938 Physies of metal cutting, pp. 1-34. Machining of metals, pp. 177, Am. Soc. for Metals, Cleveland, 0.

Houwink, R. 1937 Elasticity, plasticity and the structure of matter, pp. 376, Cambridge Univ. Press, Cambridge.

KIsser, J. 1927 Methoden zur Bestimmung der Winkelgrössen an Mikrotommessern. Zeit. f. wiss. Mikroskopie, Bd. 44, S. $452-459$.

NádAr, A. 1931 Plasticity, a mechanies of the plastic state of matter, pp. 349, McGraw-Hill Book Co., N. Y.

Okоsнi, M., AND S. Fukui 1933 Researches on the eutting action of planing tool, by mikrokinematographic, photoelastic and piezoelectric methods. Sci. Papers Inst. Phys. and Chem. Res. (Tokyo), vol. 22, pp. 97-166.

RICHARDs, O. W. 1942 The effective use and care of the microtome. Spencer Lens Co., Buffalo, N. Y. (In press).

Rosenhain, W., and J. L. Haughton 1935 An introduction to the study of physical metallurgy, pp. 368, Constable and Co., London.

Skinner, E. W. 1940 The science of dental materials, pp. 421, W. B. Saunders, Philadelphia. 